\title{
INTERESTS, WRONGS, AND THE INJURY HYPOTHESIS
}

\author{
Richard Healey
}

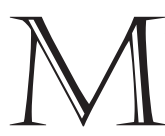

ANY PHILOSOPHERS HOLD that there is an important explanatory and justificatory connection between interests and wrongs. ${ }^{1}$ But interest-based accounts of wronging face a significant challenge: we believe many acts constitute wrongs whether or not they set back an individual's interests. Consider a case described by Arthur Ripstein:

Suppose that, as you are reading this in your office or in the library, I let myself into your home, using burglary keys that do no damage to your locks, and take a nap in your bed. I make sure everything is clean. I bring hypoallergenic and lint-free pajamas and a hairnet.... I do not weigh very much, so the wear and tear to your mattress is non-existent. By any ordinary understanding of harm, I do you no harm. ${ }^{2}$

Despite his doing you no harm, we clearly believe Ripstein wrongs you. How, though, can an interest-based theory explain such cases of harmless wronging? In Shaping the Normative Landscape, David Owens develops a novel solution. ${ }^{3}$ Owens argues that, in order to explain harmless wrongs, we must postulate normative interests, interests in normative phenomena such as wrongs and obligations. My aim here is twofold. First, I argue against Owens's solution to cases of harmless wronging (sections 1 and 2). Second, and more generally, I show that cases of harmless wronging only pose a problem for interest-based theories if we accept a significant assumption about the relationship between interests and wrongs (section 3 ).

1 In this article, I am only concerned with the relational form of wrong that involves one agent's wronging another (e.g., A's wronging $B$ ). I will refer to this as a wrong or wronging interchangeably.

2 Ripstein, "Beyond the Harm Principle," 218.

3 All parenthetical references are to this work. 


\section{NORMATIVE INTERESTS AND EXPLANATION}

Many people recognize the intuitive connection between interests and wrongs. Plausibly, this is because we recognize a connection between making an agent's life go worse and wronging them. This connection would seem to be naturally expressed in what Owens calls the injury hypothesis: ${ }^{4}$

Injury Hypothesis ( $\mathrm{IH})$ : An act wrongs $X$ in virtue of being an action against some interest of $X$ 's. ${ }^{5}$ (61)

However, cases of harmless wronging pose a problem for $\mathrm{IH}$. According to $\mathrm{IH}$, it is a necessary (although not sufficient) condition on an act's being wrong that it sets back the interests of an individual. But many actions-e.g., Ripstein's harmless trespass-are widely recognized to constitute wrongs that do not set back the interests of any individual.

Owens seeks to solve this problem, and maintain the connection between interests and wrongs, by claiming that we do in fact have an interest in cases of harmless wronging, albeit an interest of a different kind. ${ }^{6}$ Specifically, Owens postulates normative interests, interests that take "normative phenomena as [their] object, [interests] in which thoughts, feelings, and actions are obligatory, blameworthy, appropriate, or even intelligible" (vi).

In order to make this idea concrete, I focus on cases involving consent (or a lack of it), such as Ripstein's harmless trespass. Here, Owens postulates a permissive interest: an interest in being able to "determine by declaration whether something constitutes a wronging” (172). So, for example, Owens holds that the interest that underpins my power of sexual consent is not an interest in having control over whether others have sex with me, but is "an interest in its being the case that one is wronged by [sex] unless one consents to it" (181). ${ }^{7}$ Likewise, I assume, the interest that grounds my power of consent over my property is an interest in its being the case that I will be wronged by the use of my property unless I consent to it. Unlike nonnormative interests, however, normative interests can only ground wrongs in the context of a suitable social convention $(9-10,65,150)$.

4 Owens claims that the injury hypothesis is "widely accepted" and attributes the view to Joseph Raz, T. M. Scanlon, Judith Jarvis Thomson, and J. S. Mill (61n28).

5 Owens also allows that the adoption of an attitude may set back another's interests. This complication does not bear on my argument, so I set it aside for present purposes.

6 However, Owens does not endorse the injury hypothesis himself. See section 3.

7 Importantly, Owens maintains that our normative interests are not reducible to any nonnormative interest - that is, to any more familiar interest in nonnormative phenomena such as control over one's life, pleasure, or knowledge (65). 
For example, the harmless trespass will only constitute a wrong within the context of a convention of property rights.

So, Owens claims we can account for cases of harmless wronging if:

(i) We postulate a normative interest (e.g., a permissive interest), and

(ii) A convention instantiates the wrong in question, thereby serving the normative interest (e.g., property conventions instantiate the wrong of trespass, and serve the permissive interest).

However, I do not believe we can offer a meaningful explanation of why $\phi$-ing constitutes a wrong - that draws on the intuitive connection between interests and wrongs-by simply postulating an interest in $\phi$ 's being wrong. For an interest of $X$ 's to help explain why $Y$ may wrong $X$ by $\phi$-ing, we must recognize the way in which $\phi$-ing will (or at least can) make $X$ 's life go worse.

Consider two examples. If I claim that $Y$ will wrong $X$ by setting him on fire I can (partially) explain this by appealing to the fact that setting $X$ on fire will cause him to suffer excruciating pain and thereby make his life go much worse. Since we recognize the general claim that making someone's life go worse will often wrong them, and we recognize that $Y$ 's setting $X$ on fire will make $X$ 's life go much worse, we have a clear (if incomplete) explanation as to why $Y$ will wrong $X$ by setting him on fire. By contrast, imagine that Sally claims that $Y$ will wrong $X$ - who lives on another continent - by singing a nursery rhyme. We ask Sally why this would be. She says that it is because $X$ has an interest in $Y$ 's not singing nursery rhymes. But while this seems to fit the argumentative schema (because it appeals to a purported interest of $X$ 's that $Y$ will set back), it does not offer an illuminating explanation of why $Y$ will wrong $X$ by singing. That is because we do not recognize how Y's singing could make $X$ 's life go any worse. If Sally is to explain or justify her claim, she must do more than simply say that $X$ has an "interest" in $Y$ 's not singing. She must further show us how $Y$ 's singing will make a difference to how $X$ 's life goes.

The problem for Owens is that his claim, for example, that a harmless trespass is wrong because we have a permissive interest is in the relevant respects like Sally's claim that $X$ has an interest in $Y$ 's not singing a nursery rhyme. Put generally: it is not clear why our lives go better because certain acts are recognized to constitute wrongings within certain social conventions, independently of the effect these conventions will have on our nonnormative interests. For instance, the idea that an individual's life goes better just because it is socially recognized that it is wrong to use her property without her consent is not, I contend, a recognizable human interest. Thus, appealing to the permissive interest to explain cas- 
es such as the harmless trespass does not provide the kind of explanation that makes interest-based accounts appealing.

Of course, this is not news to Owens. His strategy is to postulate normative interests, and so to assume, for the purposes of his discussion, that the social recognition of harmless wrongs makes our lives go better. My point is just that unless we are offered independent grounds for thinking that we have normative interests-grounds that are independent of the fact that these interests can explain why harmless wrongs constitutes wrongings - we cannot rely on normative interests to explain harmless wrongs. The permissive interest is just, at this stage, a placeholder for the very thing that we seek to explain. ${ }^{8}$

\section{OWENS'S THEORY OF WRONGS}

It might be suggested that, given the difficulty of accounting for harmless wrongs, we should accept this explanatory deficit. However, accepting the postulation of normative interests has further implausible consequences for the structure of Owens's theory of wrongs.

First, on Owens's view, many wrongs are divorced from the nonnormative interests we previously took to explain them. This is a consequence of Owens's claim that the primary or central wrong in any case where there is a conceptually possible harmless instance of that wrong is a harmless wronging. For example, we usually believe that doctors wrong their patients by acting without their consent because we recognize patients' significant nonnormative interests in having control over their own lives, bodily integrity, and so forth. But according to Owens, the wrong of operating without consent is instead grounded in a permissive interest. This is because there are conceptually possible harmless instances of this wrong - that is, cases of nonconsensual surgery that are harmless. ${ }^{9}$

If Owens is correct, we must significantly revise our understanding of the nature of these wrongs. But this is counterintuitive for several reasons. First, in the statistically central cases of these wrongs, victims have weighty nonnormative interests that are set back, and it seems plausible that it is the significance of these nonnormative interests that primarily motivates our concern with these cases. ${ }^{10}$

8 See further Bennett, "A Review of David Owens' Shaping the Normative Landscape," and Markovits, "Authority, Recognition, and the Grounds of Promise."

9 This might be disputed, but I am assuming it here for the sake of argument.

10 Owens maintains, against this, that cases of harmless wronging show that, "For analytical purposes, the central cases ... are the statistically peripheral ones in which no harm aggravates the primary wrong" (177). This claim gives rise to interesting methodological questions that I cannot address here. 
Furthermore, divorcing all consent-related wrongs from nonnormative interests has the implication that the wrong of acting without consent always depends upon the existence of an appropriate social convention, because, as we saw above, normative interests only ground wrongs in the presence of social conventions. Thus, as Owens notes, his theory has the striking consequence that "breach of promise, disloyalty in friendship, and even rape (in abstraction from the harm it causes) constitute wrongs only against a background of social convention" (9). Yet, while perhaps not implausible in all cases, surely the central egregious wrongs of rape, or of nonconsensual human experimentation, do not depend on the existence of social conventions. ${ }^{11}$

Owens may respond by pointing out that he is clear that there are usually secondary and convention-independent wrongs grounded in nonnormative interests. While not related to our power of consent, Owens claims that these secondary wrongs are affected by the normative significance of the choices we make (ch. 7). Yet this response leads to the second counterintuitive structural implication of Owens's view: in the statistically central cases of many wrongs, there is a doubling of wrongs. That is because there will generally be a wrong grounded in a normative interest as well as a wrong grounded in a nonnormative interest. For example, a surgeon may perpetrate both a harmless wronging, grounded in the patient's permissive interests, as well as a harmful wronging, grounded in the patient's nonnormative interests. Yet, claiming there are two wrongs in such cases is implausible. Imagine that after an operation a patient complains that the surgeon has wronged him because, despite giving consent to undergo the operation, he did not choose the surgery. ${ }^{12}$ Surely the patient is mistaken: if he gave free and informed consent to the operation then the surgeon has not wronged him because he did not also choose the surgery. ${ }^{13}$ Yet for Owens, if we assume the truth of the patient's claim, he is correct (181).

Of course, conventions of consent may well shape what morally permissible relations consist in. Conventions of sexual consent may, for example, serve to make what constitutes morally permissible sexual relations more determinate in different contexts. The point is just that, as participants in the ongoing debate about how to characterize the central wrong of rape would seem to agree, the basic wrong of rape is not essentially conventional. Choosing the surgery, on Owens's rendering, requires him to intend for the surgery to go ahead (173).

13 To be clear, I am not claiming that there is no way that the patient could have been wronged by consensual surgery. They could have been so wronged if, for example, the surgeon violated a fiduciary duty. What I am claiming is that they could not have been wronged by surgery that they consented to even if they did not choose it. 


\section{THE INJURY HYPOTHESIS}

Owens may respond by suggesting that if we are committed to an interest-based account of wronging, we must postulate normative interests in order to account for harmless wrongs, even if this means accepting some seemingly counterintuitive results. Alternatively, we may be tempted to give up on the intuitive connection between interests and wrongs altogether. Indeed, Ripstein introduces the example of harmless trespass in order to motivate a move away from Mill's harm principle to an alternative sovereignty principle. ${ }^{14}$

However, we are only forced to choose between postulating normative interests - and accepting the difficulties with Owens's theory that I have highlighted-or rejecting the intuitive connection between interests and wrongs altogether, if we have reason to endorse $\mathrm{IH}$. That is because it only follows that interest-based theories are unable to account for harmless wrongings if we accept as a necessary condition on an act's being wrong that it must set back an interest of the victim. Do we, then, have reason to endorse IH? Since I cannot consider the plausibility of $\mathrm{IH}$ in detail here, I will defend a relatively weak claim: those who give nonnormative interests a central role in their theory of wronging are not required to endorse $\mathrm{IH}^{15}$ That is to say, there is conceptual space within which to develop accounts of the relationship between interests and wrongs that do not incorporate IH. ${ }^{16}$ Indeed, Owens himself rejects IH (64). But while Owens sometimes gives the impression that his rejection of $\mathrm{IH}$ is connected to

14 Ripstein, "Beyond the Harm Principle."

15 As an interpretive matter, I do not think it is clear that all the authors Owens cites as holding the view (viz., Raz, Scanlon, Thomson, and Mill) really do hold it. I cannot pursue this interpretative question here.

16 Defenders of interest-based theories might also argue that, in the cases of purportedly "harmless" wronging under consideration, we in fact have noninstrumental interests in having control over what happens (to us or to our property), and that these interests will be set by the act in question. Importantly, on this view, our control interests will be set back by the wrongdoer's action independently of whether this will have any further effect on how our life goes. If this claim can be defended, this would allow us to accept IH while accounting for cases of ostensibly harmless wronging. However, while I am sympathetic to the idea that we have such interests in many cases (e.g., with regard to our sexual relationships), I suspect that our conviction that harmless wrongs are genuine wrongs does not depend upon our belief that we can find an interest that will be set back in every proposed case of harmless wronging. Rather, I think that our beliefs about these cases flow from a more deep-rooted (albeit inchoate) view about the nature of wrongs, according to which the correct account of the relationship between interests and wrongs does not incorporate $\mathrm{IH}$. Thus, one of my main aims in this article is simply to challenge $\mathrm{IH}$, leaving a full consideration of other argumentative strategies for another occasion. Thanks go to an anonymous reviewer for urging me to consider this possibility. 
the postulation of normative interests, there is no reason to think that we must postulate normative interests before we are entitled to reject $\mathrm{IH}$.

To see this, note first that IH implicitly depends upon a form of consequentialism about wronging: according to $\mathrm{IH}$, if $Y$ is to wrong $X$ by acting it must be the case that $Y$ 's action is an action against some interest of $X$ 's. I take it that this means that the action must cause the setting back of X's interest; if $Y$ 's act does not cause the setting back of $X$ 's interest then it fails to bring about a consequence that is a necessary condition upon an act's being wrong. If this is correct, however, $\mathrm{IH}$ depends on controversial consequentialist assumptions about the relationship between values (in this case wellbeing) and wrongs. ${ }^{17}$ Rather than postulating normative interests, or rejecting interest-based theories outright, we may prefer to reject the implicit consequentialism that forces this choice upon us. ${ }^{18}$

Unsurprisingly then, in order to show that a conception of wrongs need not incorporate $\mathrm{IH}$, we need look no further than a nonconsequentialist theory of wrongs. For illustrative purposes, consider T.M. Scanlon's popular account of contractualism. According to Scanlon, an act is wrong if its performance would be disallowed by principles that no one could reasonably reject. ${ }^{19}$ Whether Scanlon's principle implicitly endorses IH is an open question. But there is good reason to think that it need not. Indeed, Rahul Kumar has argued that part of the appeal of Scanlonian contractualism is that nothing like IH holds. ${ }^{20}$ On Kumar's reconstruction, principles that could not be reasonably rejected serve to "fix what the general terms are for relating to one another ... by establishing certain legitimate expectations concerning considerations and conduct between persons." ${ }^{21}$ We wrong one another, on this view, if we fail to abide by these legitimate expectations.

What is crucial for our purposes is the point at which interests can enter the foregoing story-namely, as grounds for the reasonable rejection of principles. For instance, I may reasonably reject a principle that licenses others to use my bed when they wish because of my interests in autonomy, privacy, etc. As such, I may form legitimate expectations that others refrain from breaking into my

See Kumar, "Defending the Moral Moderate," 278-79, and the references therein, for discussion of a closely related point.

I am not making the strong claim that consequentialist theories must accept IH. I merely want to make clear that IH would seem to presuppose a form of consequentialism about wronging. It does seem, however, that nonconsequentialists will have more resources to motivate views that do not endorse IH.

See Kumar, "Defending the Moral Moderate" and "Who Can Be Wronged?"

Kumar, "Who Can Be Wronged?" 106. 
house and using my bed. When others violate these legitimate expectations, they wrong me by doing so whether or not they set back any of my interests on this occasion. What matters is that, given my interests, I can have certain legitimate expectations of others, and I will be wronged when they violate these expectations. On this account, then, the connection between interests and wrongs is indirect: whether $Y$ wrongs $X$ depends upon whether $Y$ violates a principle that $X$ could reasonably reject; whether $X$ can reasonably reject a principle will depend (in many cases) upon $X$ 's interests.

In summary: I have argued that Owens's solution to cases of harmless wronging fails to be explanatory, and has implausible consequences for his theory of wrongs. Furthermore, I have shown that the argumentative significance of these cases requires that we accept a substantive and questionable assumption about the relationship between interests and wrongs. ${ }^{22}$

\section{McGill University and Centre de Recherche en Éthique richard.healey@mail.mcgill.ca}

\section{REFERENCES}

Bennett, Christopher. "A Review of David Owens' Shaping the Normative Landscape." Jurisprudence 6, no. 2 (2015): 364-70.

Kumar, Rahul. "Defending the Moral Moderate: Contractualism and Common Sense." Philosophy and Public Affairs 28, no. 4 (Autumn 1999): 275-309.

-. "Who Can Be Wronged?" Philosophy and Public Affairs 31, no. 2 (Spring 2003): 99-118.

Markovits, Daniel. "Authority, Recognition, and the Grounds of Promise." Jurisprudence 6, no. 2 (2015): 349-56.

Owens, David. Shaping the Normative Landscape. Oxford: Oxford University Press, 2012.

Ripstein, Arthur. "Beyond the Harm Principle." Philosophy and Public Affairs 34, no. 3 (Summer 2006): 215-45.

Scanlon, T. M. What We Owe to Each Other. Cambridge, MA: Harvard University Press, 1998.

22 Thanks go to Jason D’Cruz, Jens Gillessen, Angie Pepper, Sarah Stroud, and an anonymous referee for JESP for helpful comments on an earlier version of this article. 